\title{
Migration Application from Waterfall to Agile Environments for Effectiveness and Efficiency Strategy
}

\author{
Calandra Alencia Haryani ${ }^{1}$, Hery $^{2}$, Andree E Widjaja ${ }^{3}$, John Tampil Purba ${ }^{4}$ \\ \{calandra.haryani@uph.edu ${ }^{1}$,hery.fik@uph.edu², andree.widjaja@uph.edu ${ }^{3}$ \} \\ Universitas Pelita Harapan, Jl. MH. Thamrin Boulevard 1100, Karawaci, Tangerang, Banten, \\ Indonesia ${ }^{1234}$
}

\begin{abstract}
PT XYZ faced a challenge to compete in the telecommunication industry. by migrating from previous Waterfall Approach to Agile Approach, they expected to speed up the completion of their project compared to prior approach. However, the result proved to be different then what they had targeted. The project suffers from delay completion while in theory, they should have worked better and faster then Waterfall approach. This paper approach is to identify what are the challenge that should be resolved while migrating from Waterfall Approach to Agile Approach. The Critical Success Factor shall be identified and compared with the data gathered from each participant of Agile Project during 1st November 2017 to 28th February 2018n period. The Result of this paper should serve as a guideline for stakeholders of PT XYZ to solve and improve their underlying condition
\end{abstract}

Keywords: migration application, waterfall, agile, effective and efficient, strategy.

\section{Introduction}

The ICT sevices of most business industries and organizations in the world influence attractively to their customers as well as clients from time to time. Among of them such as; banks, hospitals, manufactures, insurances, telecommunications, contractor, and governments [1]. The usage of the infromation and communication technology to support their activities will be better, faster, effective and accurate and efficiently services towards their clients, customers and also citizens [2],[3]. This research paper discuss about the implementation of ICT project management application in the one of Indonesia's Largest Telecommunication Company, PT XYZ was founded in 1995, and has spread its telecommunication access service throughout all locations in Indonesia. The company has established itself as a "Go-To" company when it comes to providing telecommunication access whether for network service or internet service provider. With total assets of 89,8 trillion rupiahs, supported by 5.191 employee, and assisted by 129 thousand of BTS, they were able to serve around 173,9 million active subscribers around Indonesia Interms of financial gain, the company has total income of 86,7 trillion rupiahs in 2016 with profit of 28.2 trillion rupiahs [4].

Besides providing services to conventional customer, PT XYZ has a unit department of $\mathrm{M} 2 \mathrm{M} / \mathrm{IoT}$ and $\mathrm{B} 2 \mathrm{~B}$ to provide digital solution service to handle different kind of project management solution needed by its customer. However, since their migration from Waterfall to Agile Approach, they suffer several setbacks, mainly a project delivery postponement.

ICCSET 2018, October 25-26, Kudus, Indonesia

Copyright $@ 2018$ EAI

DOI 10.4108/eai.24-10-2018.2280544 
Table 1 is gathered based on PT XYZ Project Report from 1st November 2017 to 28th February 2018 period, which shown that only $58.33 \%$ of project is completed on time; which is 7 out of 12. That is below customer expectation that wanted their project to be completed on time. However, it is believed that the reason of project lateness is because of improper Agile method execution. As there are a number of ICT applications in project management, but this paper derived from empirical evidence in Telcom company in Indonesia that has been succefully implemented compared to existing ones that usually fail to achive faster scheduled. This is consider to be the original which believed give contributions to local contractors or owners projects in this country and or other countries as well.

The purpose of this paper is to identify what is the challenge needed to be resolved after migrating from Waterfall to Agile approach, as it is believed that Agile method ensure acceleration project delivery, fulfilled customer satisfaction, and high-quality product which is not the case with PT XYZ. Proper execution of Agile method would be resolved by overcoming each challenge identified for Agile method in PT XYZ Case.

Tabel 1. PT XYZ Project Report

\begin{tabular}{lll}
\hline No & Project Name & Status \\
\hline 1 & Fixing Incident Gift transaction for Reseller Partner On Same & Meet Target \\
2 & Service Implementation for Enterprise Application Store & Meet Target \\
3 & Application for adding portal package CUG Eaac Corporate & Meet Target \\
4 & Application Enchancement Service B2B2C Corporate & Meet Target \\
5 & T-Bike Fleet Management Services & Meet Target \\
6 & CUG Mygroup LE Enhancement & Meet Target \\
7 & Application for Service Implementation Enterprise Application Store & Meet Target \\
8 & Q1-2017-BR5192-Plan-T-Bike Fleet Management Services & Delay \\
9 & Packet Implmentation MitraPro dan MitraData & Delay \\
10 & Change Request for Portal Eaac Corporate & Delay \\
11 & Unplan-Enterprise as a Channel (EAAC) & Delay \\
12 & Fix Mobile Convergence & Delay \\
\hline
\end{tabular}

\section{Literature Review}

The usage of high-end information technology with appropriate applications will provide the tools for competitive advantage in delivering services to the customers and it will become very valuable and more efficiency in facing the globalized market. This idea of combination IT innovations and in the context of any similar or other business [5], [6], [7].

\subsection{Waterfall}

Waterfall method is a project management approach by sequentially following determined process step. The Standard Waterfall Model Process is as follows:

System Requirements $\rightarrow$ Software Requirements $\rightarrow$ Analysis $\rightarrow$ Design $\rightarrow$ Implementation $\rightarrow$ Testing $\rightarrow$

Operating. 
The rule is that each task must be completed before moving into the next one, and if the current steps couldn't be resolved, the developer should go back to earlier step and re-adjust the task. This approach is often considered as the typical traditional approach when doing Project Management or Software Development. The advantage of this method is a clear focus of task as each member could focus on given on-going task and completed given step accordingly before moving on into another task. The project also become easy to control by its project manager or customers, as it maintains time, budget, and scope according to Initial System Requirements [8].

\subsection{Agile}

As ICT aplication gives a lot of contributions in the rapid transformation in global society, that can provide flexible management in the various projects activities [9]. Agile method is an iterative project management approach, aim to deliver the product in short period of time with continuous changing of business requirement. Every service industry which willing to sustain shall be follow the recent technology that has good acceptance and agility [10]. Agile method divided into sub-goals that must be completed and added into project backlog. There are three requirement prepositions process in agile development [11]:

a. Environment Analysis: Stakeholder, Project Constraint, Project Requirement.

b. Process: Select stakeholder, select prioritization technique, prioritize requirements, prioritize project backlog, plan for iteration, sprint backlog, implement iteration.

c. Product: High Quality Requirement and Customer Satisfaction,

\subsection{Waterfall and Agile differences}

In terms of Requirement characteristic, Waterfall methodology has a clear defined requirement in their System Requirement step, the process usually is time consuming as they must properly defined user needs and expectation while also analyzing the compatibility with current condition. The user involvement is limited in Waterfall Method, as they only involve during Requirement and Implementation Process. While in Agile methodology, the user is close and has frequent collaboration with team members to provide input and idea. As a result, the documentation is limited to tacit and notes, contrast to Waterfall methodology with formal complete documentation. This is due the fact that Waterfall project size is larger compared to small-to-medium project in Agile methodology. Therefore, system failure in waterfall has serious consequences compared to Agile. However, Agile methodology is not for everybody, the organization should be prepared to embrace the complex and iterative agile approach, while collocated team is also desired [12]. The traditional Waterfall approach in comparison is using rigid process and has accentuated and distributed team.

Table 2. Differences between Waterfall and Agile

\begin{tabular}{|c|c|c|}
\hline Characteristic & Waterfall & Agile \\
\hline Requirement & Clear initial requirements & $\begin{array}{l}\text { Creative, innovative, unclear } \\
\text { requirements }\end{array}$ \\
\hline Users & Not involve & Close and frequent collaboration \\
\hline Documentation & Formal & Tacit knowledge \\
\hline Project size & Bigger projects & Smaller projects \\
\hline $\begin{array}{l}\text { Organization } \\
\text { Support }\end{array}$ & Use existing processes bigger organization & $\begin{array}{l}\text { Prepared to embrace agile } \\
\text { approach }\end{array}$ \\
\hline
\end{tabular}




\begin{tabular}{llll}
\hline Team members & $\begin{array}{l}\text { Not accentuated; fluctuation } \\
\text { distributed team }\end{array}$ & expected, & Collocated team; smaller team \\
$\begin{array}{l}\text { System } \\
\text { criticality }\end{array}$ & System failure consequences serious & Less critical system \\
Project Plan & Linear & Complex, iterative \\
\hline
\end{tabular}

\subsection{Critical Success Factor for Agile Methodology}

Based on research by Chow and Cao in 2007, a framework is constructed to be used to determine Critical Success Factor for Agile Methodology implementation, which is divided into Dimensions such as Organizational, People, Process, Technical, and Project; each of dimensions are described in above table. Each of its factor would be used as guidelines in this research to determine what is the Critical Success Factor missing in the PT XYZ that hinderance their project chow [13].

Table 3. Critical Success Factor Agile.

\begin{tabular}{|c|c|}
\hline DIMENSION & FACTOR \\
\hline ORGANIZATIONAL & $\begin{array}{l}\text { 1. Strong Executive Support } \\
\text { 2. Committed Sponsor } \\
\text { 3. Cooperative Organization Culture } \\
\text { 4. Oral culture placing high value on face to face communication } \\
\text { 5. Organization accepted agile universally } \\
\text { 6. Collocation of whole team } \\
\text { 7. Facility with proper agile-style work environment } \\
\text { 8. Reward system appropriate to agile }\end{array}$ \\
\hline PEOPLE & $\begin{array}{l}\text { 1. Team member with high competence and expertise } \\
\text { 2. Team member with high motivation } \\
\text { 3. Manager knowledge in agile process } \\
\text { 4. Manager have adaptive management style } \\
\text { 5. Coherent-self organizing teamwork } \\
\text { 6. Good customer relationship }\end{array}$ \\
\hline PROCESS & $\begin{array}{l}\text { 1. Follow agile oriented requirement management process } \\
\text { 2. Follow agile oriented project management process } \\
\text { 3. Follow agile oriented configuration management process } \\
\text { 4. Strong communication focus with daily face to face meetings } \\
\text { 5. Honoring regular working schedule } \\
\text { 6. Strong customer commitment/presence } \\
\text { 7. Customer has full authority }\end{array}$ \\
\hline TECHNICAL & $\begin{array}{l}\text { 1. Well defined coding standards up front } \\
\text { 2. Pursuing simple design } \\
\text { 3. Rigorous refactoring activities } \\
\text { 4. Right amount of documentation } \\
\text { 5. Regular delivery of software } \\
\text { 6. Delivering most important features first } \\
\text { 7. Correct integration testing } \\
\text { 8. Appropriate technical training to team }\end{array}$ \\
\hline PROJECT & $\begin{array}{l}\text { 1. Project nature being non-life-critical } \\
\text { 2. Project type being of variable scope with emergent requirement }\end{array}$ \\
\hline
\end{tabular}



3. Project with dynamic, accelerated schedule
4. Project with small team
5. No multiple independent teams
6. Project with up-front cost evaluation done
7. Project with up-front risk analysis done

\section{Research Methodology}

\subsection{Data Collection}

Data collection process is based on quantitative data analysis methodology by using questioners that would be spread throughout each members of team that has previously involved in Agile methodology approach for PT XYZ's Project during 1st November 2017 to 28th February 2018 period. Questionnaire sampling is given to 35 members of all completed project through email, and the feedback response to the questionnaire is 24 out of 35 in which is equal to $68,5 \%$ response rate. There is no distinction criteria between user sampling as it focus more on technical aspect of the Agile method implementation.

Every factor attribute in questioner would be given Ranked by Data Interval between: 1(one)-to-10(ten)-point degree of importance, where 1(one) indicate less related while 10 indicate more related. The Content of each question would be based on the Critical Success Factor for Agile Methodology, as an indicator to relate real problem condition of PT XYZ compared to the Critical Success Factor. Furthermore, to gain more understanding in subject matter, a comment column would be given in each questionnaire point to provide an opportunity for the user to give a feedback that would be useful in data analysis process., while also give an insight for the researcher to interpret the data.

\subsection{Data Analysis}

Data gathered would be analyze by comparing the result gathered during data collection with the Critical Success Factor of Agile methodology implementation. The Data Interval gathered during data collection, would be presented in number by calculating its mean or average. The Highest average number would indicate those factor dimension that affected the Critical Success Factor for Agile Implementation. Moreover, The Result of Analysis will be presented in the graphical Statistical form and analyzed to gain more understanding about the subject matter intended to be solved. 


\section{Result}

Based on the results of the questionnaire received from the five domains of critical success factor agile consisting of organizational factor, people factor, process factor, technical factor, and project factor have been obtained for factors that affect each domain. In the domain of organizational factor, the most influencing factor of successful agile implementation in PT.XYZ is strong executive support with an average yield of 9.04. Figure 1 is a graph of the average result of the organizational factor for the critical success factor agile.

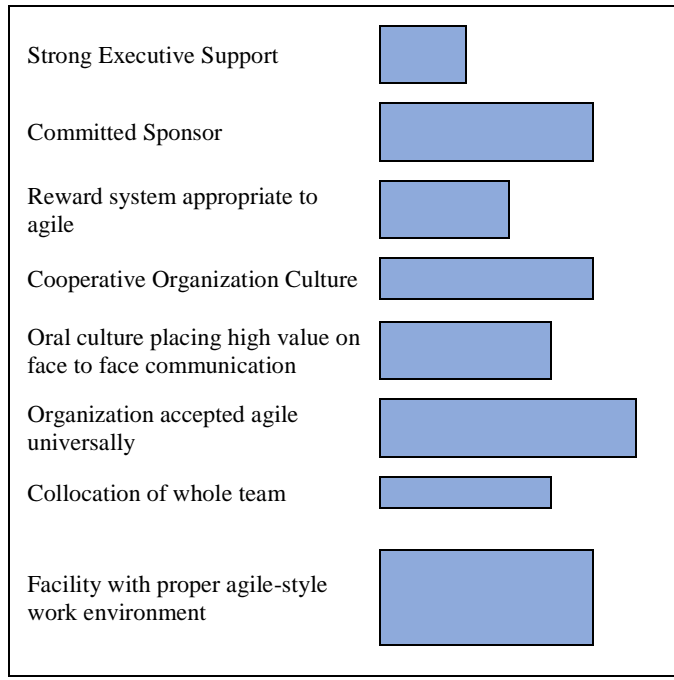

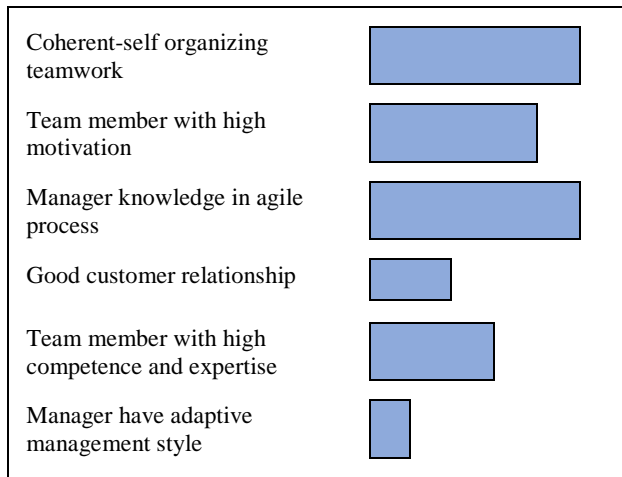

Fig. 2. People Factor.

Fig. 1. Organizational Factor.

In the domain people factor, the six factors in this domain have a fairly high average value that reflects the six factors that are actually all related to the success of agile implementation in the project. However, team member factor with high motivation get the highest average with value 8.91. This proves that team member with high motivation factor take an important role in success of agile implementation in PT XYZ. Picture 2 is a graph of average result from people factor for critical success factor agile.

In the domain of process factor, the target factor of this domain has a fairly high average value which is similar with people factor. This result reflecting from its seven factors as there are some relevance to the success of agile implementation in the project. However, a strong communication factor focuses on face to face meetings is the most influencing factor of successful agile implementation in PT XYZ with an average yield of 9.2. Figure 3 is a graph of the average result of the process factor for the critical success factor agile. 


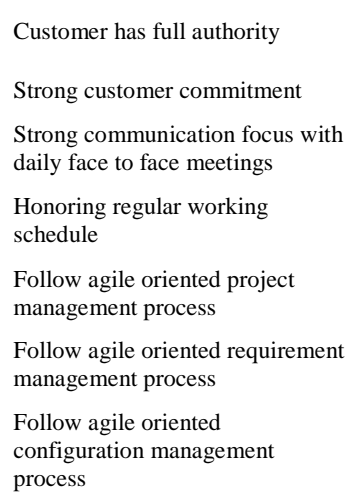

Fig. 3. Process Factor

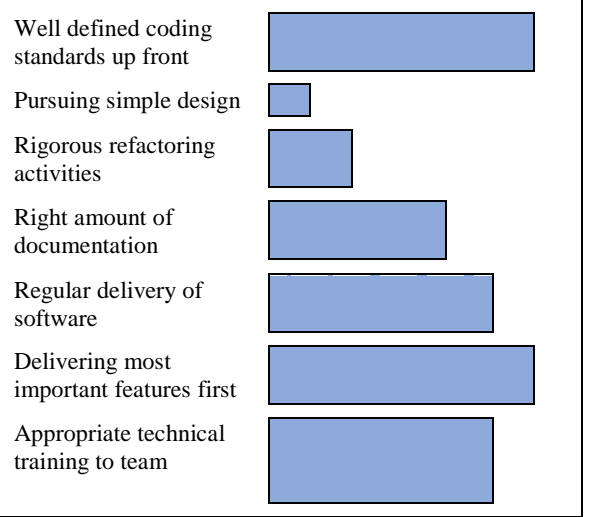

Fig. 4. Technical Factor.

For domain technical factor, there are eight factors that influence the success of agile implementation. The most influencing factor in the success of agile implementation in the project is the Delivering Most Important Feature First factor with an average value of 8.75. Figure 4 is the average yield graph of the technical factor for the critical success factor agile. In the domain of project factors, the average results for the seven factors within the projectfactor domain are not very high when compared with the average result of other factors in the organizational, people, process, technical, and project domains. It is possible that the factors that exist in the domain project does not significantly affect the success of agile implementation for PT.XYZ. However, the factor in this domain that gets the highest average value is project with dynamic and accelerated schedule. Figure 5 is the average result of the project factor for the critical success factor agile.
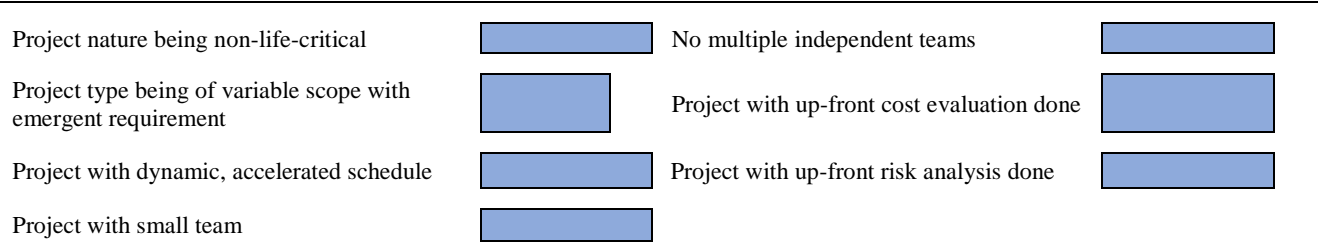

\section{Conclusion and Recommendation}

Based on the results of the questionnaires discussed in Chapter 3, PT XYZ should be able to focus on several factors to be able to change the method from waterfall to agile. This research uses critical success factor for successful implementation of agile which has been studied previously by Chow and Cao in 2007 which is considered suitable to be implemented also in research for PT XYZ. Based on Chow and Cao's research in 2007 there are five domains of factors consisting of organizational, people, process, technical, project factors described earlier in chapter 2. PT XYZ should be able to focus on strong executive support factor in organizational domain, team factor with high motivation in the domain people, string 
factor communication agile implementation on face to face meeting in domain process, factor delivering most important feature first in technical domain, and last project factor with dynamic and accelerated schedule in domain project. This research only get response rate equal to $68,5 \%$, it would be better if response rate to questioner reach $75 \%$. However, the results of this research have been able to answer and provide input to PT XYZ and can be the basis for other advanced research related to challenges in migration from waterfall to agile environment.

\section{References}

[1] J. T. Purba, "Usage of IT Services in Higher Education Management for Innovation Strategy: A case study.," in Proceeding. Presented in the International Conference and Organizational Innovation (ICOI 2014) De La Salle University System, 2015.

[2] J. . Purba, "Applied ICT Innovation Services of Academic Information System: Strategy for Higher Educational Management," in International Conference of Organizational Innovation (ICOI), 2015.

[3] J. Tampil Purba and R. Panday, "Innovation strategy services delivery: An empirical case study of academic information systems in higher education institution," in Communications in Computer and Information Science, 2015, vol. 516, pp. 514-525.

[4] D. B. Management, "Daftar Status Project pada B2B \& M2M System Management. PT Telkomsel," 2018.

[5] P. Y. Radnan and J. T. Purba, "The Use of Information Communication Technology (ICT) As the Technology Acceptance Model (TAM) of Mobile Banking," J. Manaj. dan Pemasar. Jasa, vol. 9, no. 2, pp. 283-298, 2016.

[6] J. . Banuara, S. \& Purba, "Analysis of the Aviation Industry in Indonesia Period 2003-2015 based on Domestic Passenger Growth and the Strategic Implication for Airline and Government," $J$. Manaj. dan Pemasar. Jasa, vol. 10, pp. 10-11, 2017.

[7] R. Panday and J. T. Purba, "Lecturers and students technology readiness in implementing services delivery of academic information system in higher education institution: A case study," in Communications in Computer and Information Science, 2015, vol. 516, pp. 539-550.

[8] S. A. Schuh, G., Rebentisch , E., Riesener, M., Diels, F., Dolle, C., \& Eich, "Waterfall Hybrid Product Development in the Manufacturing Industry - Introducting Guidelines for Implementation of Pararell Use of the Two Models," IEEE IEEM, pp. 725-729, 2017.

[9] J. T. Purba, "Pengukuran Kualitas Layanan Unit Kerja Teknologi Informasi Menuju Strategi Tata Kelola Organisasi," in Proceeding Economic Globalization Trend \& Risk for Developing Country. FE Universitas Kristen Maranatha, 2014.

[10] J. T. Purba, "Service Performance ICT Train New Technologies Towards Orgazizations : Case Study Asindo Informatika," in . Seminar Nasional dan Call Paper "Business in Society: Towards Asian Era, FEB UNS, Surakarta 18-19 Maret 2014, 2014.

[11] R. AL-Ta'ani, R. H., \& Razali, "Prioritizing Requriement in Agile Development: A Conceptual Framework," in Procedia Technology, 2013, pp. 733-739.

[12] A. Monfared, S. S., \& Kamandi, "Agile techniques and framework based on the requriements for e-commerce application," in Second International Conference on Web Research, 2016.

[13] D. . Chow, T., Cao, "A Survey Study of Critical Success Factors in Agile Software Projects," J. Syst. Softw., pp. 961-971, 2008. 